\title{
The effects of intermittent or continuous energy restriction on weight loss and metabolic disease risk markers: a randomised trial in young overweight women
}

\author{
Michelle N. Harvie, Mary Pegington, Mark P. Mattson, Jan Frystyk, Bernice Dillon, Gareth \\ Evans, Jack Cuzick, Susan A Jebb, Bronwen Martin, Roy G. Cutler, Tae G. Son, Stuart \\ Maudsley, Olga D. Carlson, Josephine M. Egan, Allan Flyvbjerg, and Anthony Howell \\ Genesis Prevention Centre, University Hospital of South Manchester NHS Foundation Trust, UK \\ (MH, MP, GE, AH), CRUK Centre for Epidemiology, Mathematics and Statistics, Wolfson Institute \\ of Preventive Medicine, Queen Mary's School of Medicine, London, UK (JC), Department of \\ Statistics University Hospital of South Manchester, UK (BD), Clinical Institute of Medicine \& \\ Department of Endocrinology and Internal Medicine, Aarhus University Hospital, Denmark (JF, \\ AF), MRC Human Nutrition Research Group, Cambridge, UK (SJ), Laboratory of Neurosciences, \\ National Institute on Aging Intramural Research Program, Baltimore, USA (MM, BM, RC, TS, SM, \\ OC, JE)
}

\begin{abstract}
Background-The problems of adherence to energy restriction in humans are well known.

Objective-To compare the feasibility and effectiveness of IER with CER for weight loss, insulin sensitivity and other metabolic disease risk markers.
\end{abstract}

\begin{abstract}
Design-Randomised comparison of a 25\% energy restriction as IER ( $2266 \mathrm{~kJ} /$ day for 2 days/ week) or CER ( 6276 kJ/day for 7 days/week) in 107 overweight or obese (mean [ $\pm \mathrm{SD}]$ body mass index $30.6[ \pm 5.1] \mathrm{kg} / \mathrm{m}^{2}$ ) premenopausal women over 6 months. Weight, anthropometry, biomarkers for breast cancer, diabetes, cardiovascular disease and dementia risk; insulin resistance (HOMA), oxidative stress markers, leptin, adiponectin, IGF-1 and IGF binding proteins 1 and 2, androgens, prolactin, inflammatory markers (high sensitivity C-reactive protein and sialic acid), lipids, blood pressure and brain derived neurotrophic factor were assessed at baseline and after 1 , 3 and 6 months.
\end{abstract}

\begin{abstract}
Results-Last observation carried forward analysis showed IER and CER are equally effective for weight loss, mean (95\% confidence interval [CI]) weight change for IER was -6.4 ( -7.9 to $-4.8) \mathrm{kg}$ vs. $-5.6(-6.9$ to -4.4$) \mathrm{kg}$ for CER (P value for difference between groups $=0.4$ ). Both groups experienced comparable reductions in leptin, free androgen index, high sensitivity Creactive protein, total and LDL cholesterol, triglycerides, blood pressure and increases in sex hormone binding globulin, IGF binding proteins 1 and 2. Reductions in fasting insulin and insulin resistance were modest in both groups, but greater with IER than CER; difference between groups for fasting insulin $-1.2[-1.4$ to -1.0$] \mu \mathrm{U} / \mathrm{ml}$, and insulin resistance $-1.2[-1.5$ to -1.0$] \mu \mathrm{U} /$ $\mathrm{mmol} / \mathrm{L}$ (both $\mathrm{P}=0.04$ ).
\end{abstract}

\footnotetext{
Corresponding author and requests for reprints: Michelle Harvie PhD, Senior Research Dietitian, Nightingale Centre and Genesis Prevention Centre, University Hospital of South Manchester NHS Foundation Trust, Wythenshawe Hospital, Manchester, M23 9LT, UK, Tel: +44 161291 4410, Fax: +44 161291 4412, michelle.harvie@manchester.ac.uk.

None of the authors have any conflicts of interest.
} 
Conclusion-IER is as effective as CER in regards to weight loss, insulin sensitivity and other health biomarkers and may be offered as an alternative equivalent to CER for weight loss and reducing disease risk.

\section{Keywords}

intermittent; continuous energy restriction; randomised; premenopausal women; insulin sensitivity

\section{Introduction}

Excess weight and weight gain during adult life increases the risk of several diseases including diabetes (1), cardiovascular disease (CVD) (2), dementia (3), certain forms of cancer including breast cancer (4), and can contribute to premature death (5). Observational and some randomised trials indicate that modest weight reduction ( $>5 \%$ of body weight) reduces the incidence (6) (7) and progression (8) of many of these diseases. Although weight control is beneficial, the problem of poor compliance in weight loss programmes is well known (9). Even where reduced weights are maintained, many of the benefits achieved during weight loss, including improvements in insulin sensitivity, may be attenuated due to non-compliance or adaptation (10). Sustainable and effective energy restriction strategies are thus required. One possible approach may be intermittent energy restriction (IER), with short spells of severe restriction between longer periods of habitual energy intake. For some subjects such an approach may be easier to follow than a daily or continuous energy restriction (CER) and may overcome adaption to the weight reduced state by repeated rapid improvements in metabolic control with each spell of energy restriction (11).

The effect of IER on disease prevention and lifespan has been studied mainly in rodent models using a range of experimental protocols from every other day fasting to 3 weeks of partial energy restriction and refeeding. In these studies IER appears equally or more effective than isoenergetic CER for improving insulin sensitivity (12) preventing spontaneous or genetically engineered mammary tumours (13) (14), delaying the onset of prostate cancer (15), increasing resistance to neuronal damage (12), reducing cognitive impairment (16), protecting the heart (17) and increasing lifespan of rodents (18). IER may even produce similar benefits to those observed following more stringent CER (14). Few human studies have examined the effects of IER, possibly due to concerns of disordered eating patterns and over -consumption on non-restricted days. Several short term studies suggest that this does not occur $(19 ; 20)$. We report a randomised trial of $25 \%$ energy restriction delivered as IER versus CER in overweight or obese premenopausal women over a 6 month period, exploring the relative effects of the two dietary approaches on anthropomorphic and metabolic variables.

\section{Subjects and methods}

\section{Subjects}

We studied 107 premenopausal women aged 30 to 45 years with adult weight gain since the age of 20 exceeding $10 \mathrm{~kg}$, and a body mass index (BMI) between 24 and $40 \mathrm{~kg} / \mathrm{m}^{2}$. We recruited women from our Breast Cancer Family History Clinic, and women from the general population. As such, $54 \%$ of recruits had a family history of breast cancer (lifetime risk $>1$ in 6) (Tyrer Cuzick model) (21). Participants were non-smokers, not currently dieting or losing weight, with regular menstrual cycles and no evidence of hyperandrogenism or polycystic ovary syndrome (22), and no oral contraceptive use during the previous 6 months. They did not have high intakes of alcohol (>28 units/week) or phytoestrogens, and were not suffering from diagnosed diabetes, CVD, major psychiatric morbidity or cancer. We solicited participants from our Family History Clinic by mail shot, 
and women in the general population using the media and institution wide e-mails. Potential participants were screened by the study dietitians (MH, MP) to assess their physical and psychological health and motivation to lose weight, and successfully completed a 2 day trial of the very low calorie diet (VLCD) diet prior to recruitment. Of 135 who were eligible after screening, 13 (9\%) did not believe they could tolerate the diet for the 6 month trial period, a further $14(10 \%)$ decided not to participate due to social, health or work related factors (Figure 1). All participants gave informed consent. The protocol was approved by the South Manchester Ethics Committee (reference 05/Q1403/243).

\section{Study protocol}

Participants were stratified according to BMI (above or below the predicted median value 28 $\mathrm{kg} / \mathrm{m}^{2}$ ), family history of breast cancer, sedentary ( $<$ or $>1$ hour moderate activity/week), and also according to the evaluating study dietitian to ensure the 2 dietitians saw equal proportions of patients from the two treatment groups. Women were randomly assigned to 6 months of either the CER of $25 \%$ restriction below estimated requirements 7 days/week or the IER of $25 \%$ restriction delivered as a VLCD for 2 days/week with no restriction on the other 5 days/week.

Measurements were made before starting and at 1,3 and 6 months. These included weight, total body fat, fat free mass (FFM) determined by impedance (Tanita TBF-300A, Tanita Europe BV, Middlesex UK) waist, hip, bust and thigh circumference, systolic and diastolic blood pressure (BP) (Omron M5-1 Omron Healthcare Limited, Milton Keynes UK) and blood sampling. All assessments were conducted in the morning after a 12 hour fast. Weight and body fat were assessed wearing light clothing. Body circumferences were measured in triplicate according to study protocols (23). BP was measured in triplicate after 10 minutes at rest and the mean value calculated. The IER group were assessed at least 5 days after their weekly 2 day VLCD to avoid any potential acute effects of the 2 day restriction on serum markers (11). Additional fasting serum samples were however collected in a subset of the IER group $(\mathrm{n}=15)$ after either 1 or 3 months of dietary intervention to ascertain acute effects of the diet on serum markers. Samples were collected after 5 days of normal intake (Monday) on the morning after the 2 day VLCD (Wednesday) and after 2 days of normal intake (Friday) and also on these days of the week in a subset of the CER group ( $n=9)$ for comparison.

Adherence to the dietary interventions at 1, 3 and 6 months was assessed using 7-day food diaries checked for completeness with the respondent. Mean energy, protein, fat and carbohydrate intakes were estimated using the Compeat 4 Nutrition Analysis System (Carlson Bengston Consultants, London UK). In addition the IER group were asked to record whether they had successfully completed either 2, 1 or 0 days VLCD each week during the study period. We estimated the proportion of the IER and CER groups adhering to the diets at each time point defined as the numbers of IER reporting 2 or 1 day VLCD each week and the number of CER achieving a 25\% energy restriction. Physical activity was assessed using the validated international physical activity questionnaire (IPAQ) expressed as metabolic energy turnover (MET) minutes/day and kJ/day (24). Throughout the 6 month trial period participants were asked to report any adverse or positive physical or psychosocial effects of the interventions. Quality of life was assessed using the RAND SF-36 scale, reported as physical and mental component summary scores (25).

Participants were asked to record the first day of each menstrual cycle to ascertain any effects of the diets on menstrual cycle length. We did not attempt to time assessments in relation to the menstrual cycle but day of cycle was recorded and adjusted for in the analysis to account for variation in hormone and lipid biomarkers related to the cycle $(26 ; 27)$. 


\section{Experimental diets}

Both diets involved a $25 \%$ energy restriction from estimated baseline energy requirements using reported METs x estimated basal metabolic rate (28).

The CER group were prescribed a daily $25 \%$ restriction based on a Mediterranean type diet (30\% fat, $15 \%$ monounsaturated, $7 \%$ saturated fat, $7 \%$ polyunsaturated fatty acids, $45 \%$ low glycaemic load carbohydrate, and $25 \%$ protein) (29). The IER group were asked to undertake a VLCD ( $75 \%$ restriction) on 2 consecutive days and to consume estimated requirements for weight maintenance for the remaining 5 days according to the nutrient composition above. The VLCD provided 2060 to $2266 \mathrm{~kJ}$ of energy and $50 \mathrm{~g}$ protein/day and comprised 1.136 litres ( 2 pints) of semi skimmed milk, 4 portions of vegetables ( $\sim 80 \mathrm{~g} /$ portion), 1 portion of fruit, a salty low calorie drink and a multivitamin and mineral supplement. Participants were advised to maintain their current activity levels throughout the trial, and did not receive specific exercise counselling. Energy prescriptions were reviewed throughout the trial to account for changes in weight and exercise levels to maintain a $25 \%$ restriction below estimated requirements for weight maintenance.

Diets were not provided to participants but were self selected using detailed individualised food portion lists, meal plans and recipes. To maximise compliance patients received fortnightly motivational phone calls and monthly clinic appointments where weight and anthropometrics were measured and reported back to patients. All subjects were encouraged to use cognitive behavioural techniques such as self monitoring, obtaining peer/family support and stimulus control to maintain diets (30).

\section{Serum markers of disease risk}

Fasting insulin, glucose, lipid levels and sex steroid hormones were measured at the Clinical Biochemistry Department at University Hospital of South Manchester NHS Foundation Trust with the following methods: insulin (electrochemoluminescence immunoassay, Elecsys Roche Diagnostics, Lewes England, within batch coefficient of variation [CV] $1.9 \%$ ), glucose (hexokinase/glucose-6-phosphate inter-assay dehydrogenase method, Bayer Newbury England, CV 3\%), sex hormone binding globulin (SHBG) (non-competitive IRMA, IRMA-Orion Diagnostica Oy Espoo Finland, CV 2.7\%), prolactin (electrochemoluminescence immunoassay, Elecsys Roche Diagnostics, Lewes England, CV $0.8 \%$ ). Androgens were assessed using liquid chromatography and tandem mass spectrometry (LC-MS/MS) with the following CVs: testosterone 6.9\%, dehydroepiandrosterone sulphate (DHEAS) $7.3 \%$, androstenedione $2.5 \%$. Fasting insulin and glucose were combined to calculate the insulin resistance index using the homeostasis model assessment (HOMA) (31), whilst free androgen index (FAI) was also estimated by the equation $100 \mathrm{x}$ serum testosterone/serum SHBG (32). Colorimetric enzyme reactions were used to measure total cholesterol (CV 0.8\%), triglycerides (CV 1.5\%) and HDL cholesterol (CV 1.0\%) (all Roche Modular E170, Roche, UK). Levels were measured spectrophotometrically by an automated Olympus AU600 analyser. LDL cholesterol was calculated using the formula of Friedewald et al (33). The adipokines leptin and adiponectin and the inflammatory markers high sensitivity C-reactive protein (hsCRP) and sialic acid were determined at the MRC Human Nutrition Research Unit, Cambridge. Plasma leptin concentration was measured using an ELISA method (R\&D Systems, Quantikine Human Leptin kit R\&D Systems, Inc. Minneapolis, USA, CV 10\%), whilst plasma adiponectin was measured using radioimmunoassay (LINCO Research Inc., Missouri USA, CV 10\%). We also determined the ratio of leptin: adiponectin which has been linked to insulin sensitivity and breast cancer risk(34;35). 
Sialic acid was assayed using a colorimetric assay (Roche, Welwyn Garden City UK, CV $1.2 \%$ ) adapted for use on the Hitachi 912 Clinical Analyser (Roche) and hsCRP using a high-sensitivity particle enhanced turbidometric assay (Dade-Behring, Walton UK, CV $4.5 \%)$.

Total IGF-1 (CV 3.2\%), ultra-filtered free IGF-1 (CV 12\%), and binding proteins IGFBP-1 (CV 5.3\%) and IGFBP-2 (CV 5.0\%) were assayed at the Medical Research Laboratories, Aarhus University Hospital, Denmark as previously described (36) (37). Serum total ketone bodies (beta-hydroxybutyric acid ( $80 \%)$ and acetoacetone) (CV 1.6\%), brain derived neurotrophic factor (BDNF) (CV 2.9\%) and ghrelin (CV 6.7\%) were measured at the National Institute on Ageing (Baltimore, MD, USA) as previously described (38). Serum advanced oxidation protein products (AOPP) were measured using a modified method of Selmeci et al (CV 2.2\%) (39). All serum and plasma samples were stored at $4{ }^{\circ} \mathrm{C}$ for no longer than 4 hours, aliquoted and frozen at $-70{ }^{\circ} \mathrm{C}$ within 24 hours and batched so that all samples from a participant were included in the same assay (40). Laboratory personnel were blinded to the sample identity.

\section{Statistical analysis}

Data at baseline, 1, 3 and 6 months are presented as the mean (95\% confidence intervals $[\mathrm{CI}]$ ) or geometric mean $(95 \% \mathrm{CI})$ for the log transformed variables (fasting insulin, insulin resistance, adiponectin, hsCRP, total IGF-1, IGFBP-1, IGFBP-2, ghrelin, total ketone bodies, fast and slow acting AOPP, androstenedione, DHEAS, SHBG, FAI, leptin, leptin: adiponectin ratio, and physical activity [MET $\mathrm{min} /$ day and $\mathrm{kJ} / \mathrm{day}]$ ).

The primary aim of the study was to determine changes in weight and insulin resistance between IER and CER over the 6 month weight loss period. Power calculations suggested an $80 \%$ power to detect a $25 \%$ difference in change in mean insulin resistance, allowing for a $15 \%$ drop out. The primary analysis was a last observation carried forward (LOCF) analysis of variance (ANOVA) at 6 months between the groups defined at randomisation adjusted for baseline levels of each parameter, day of menstrual cycle at assessment and change in physical activity over 6 months. A baseline observation carried forward analysis and a per protocol analysis of completers only showed comparable results to the LOCF.

We also assessed changes in weight, biomarkers, dietary intake and physical activity within each of the group using paired $t$ tests at baseline and LOCF at 6 months. Statistical significance was accepted at $\mathrm{P}<0.05$ for 6 month analysis and $\mathrm{P}<0.01$ for other time points to adjust for multiple comparisons. Data were analysed using SPSS (version 14 SPSS Ltd, Chicago, IL, USA).

Changes in weight, body fat, waist and insulin resistance, over the trial period were also measured using generalised estimating equations (GEE) to allow all 3 time points to be analysed simultaneously, and to incorporate data from subjects with less than 3 time points without the need for substitution, thus increasing statistical power and a more efficient comparison across the various time points. These GEE models were constructed in Stata 10 (StataCorp LP, TX, USA) with an exchangeable correlation structure, the predictors used were the 3 time points (1, 3, 6 months), the group variable (IER vs. CER) and the group by time interaction.

\section{Results \\ Baseline data}

Characteristics of the groups at baseline are reported in Table 1. The groups were of comparable age, weight and demographics and were mainly Caucasian. A small number had 
co-morbidities, which were equally frequent in the two groups. Six IER (11\%) and 10 CER (18\%) met the Diabetes Federation Criteria for the metabolic syndrome (41). The majority of subjects reported previous attempts to diet (IER 92\%, CER 78\%), with comparable previous attempts between the groups; IER 2.8 (2.1) and CER 2.4 (1.9) $(\mathrm{P}=0.29)$.

Eighteen women withdrew from the study before 6 months (IER=11, CER=7) representing $21 \%$ IER and $13 \%$ CER subjects $\left(\chi^{2}=1.16, \mathrm{P}=0.28\right)$. The main reasons for drop out were comparable between the groups: stress (IER=3, CER=2), pregnancy (IER=2, CER=1), change in employment (IER=2, CER=1), problems adhering to the diet $(\mathrm{IER}=3, \mathrm{CER}=3)$ and personal illness (infected pacemaker, IER=1).

\section{Changes in weight, body composition and circumferences}

Weight loss was comparable between the groups. LOCF analysis at 6 months showed weight reduced from mean $(95 \% \mathrm{CI}) 81.5$ (77.5 to 85.4$) \mathrm{kg}$ to 75 (71.2 to 78.8$) \mathrm{kg}$ in the IER group compared to a reduction from 84.4 (79.7 to 89.1) $\mathrm{kg}$ to 78.7 (74.2 to 83.2) $\mathrm{kg}$ in the CER group. The percentage of women in the IER and CER groups losing 5-10\% body weight were 30 and $33 \%$ respectively, and losing $10 \%$ or more body weight were 34 and $22 \%$ respectively $\left(\chi^{2}=1.89, \mathrm{P}=0.39\right)$. Both groups experienced comparable reductions in body fat, FFM, hip, bust and thigh circumference and composition of weight loss. Percentage of weight lost which was fat in the IER and CER groups was $79( \pm 24)$ and 79 $( \pm 26) \%$ respectively $(\mathrm{P}=0.99)$ (Table 2$)$. GEE modelling over 6 months showed no group or group by month interactions for weight $(\mathrm{P}=0.41)$ (Figure 2a) or body fat (Figure $2 \mathrm{~b}$ ) $(\mathrm{P}=0.36)$ but a non-significant greater decline in waist measurement with IER at three months (mean difference between groups [95\% CI] $-1.1[-2.3$ to 0.1$] \mathrm{cm}$, group by month 3 interaction $\mathrm{P}=0.07$ ) (Figure 2c).

\section{Adherence}

Weekly dietary records were available for $82(76 \%)$ subjects at baseline, $72(67 \%)$ at 1 month, $65(60 \%)$ at 3 months and $58(54 \%)$ at 6 months. There were no significant differences in energy or macronutrient intakes between the groups at baseline. Changes in dietary intake during the study are reported in Table 3. Both groups reported reductions in average weekly energy and macronutrient intakes, however the IER group reported greater reductions for average daily intake of energy (mean difference between groups [95\% CI] $-716[-1240$ to -192$] \mathrm{kJ},-9$ [ -14 to -2$] \%, \mathrm{P}<0.01)$, protein $(-5.5[-10.0$ to -0.8$] \mathrm{g},-6$ $[-13.0$ to 0.0$] \%, \mathrm{P}=0.02)$ and carbohydrate $(-24[-41$ to -8$] \mathrm{g},-11[-18$ to -3$] \%$, $\mathrm{P}=0.004)$.

Intention to treat analysis assuming women who left the study or who did not complete food diaries did not adhere to the diets shows reported adherence to 2 days VLCD amongst the IER group to be $63 \%$ at 1 month, $43 \%$ at 3 months and $44 \%$ at 6 months. A further 7, 24, and $13 \%$ of IER subjects completed one day of VLCD at 1, 3 and 6 months respectively. The proportion of CER subjects reporting adhering to the 25\% CER was $46 \%$ at 1 month, $37 \%$ at 3 months and $32 \%$ at 6 months. Completers only analysis showed adherence to 2 days or 1 day VLCD in the IER group to be respectively 70 and $8 \%$ at 1 month, 56 and 32\% at 3 months and $64 \%$ and $19 \%$ at 6 months, whilst the $25 \%$ CER was achieved by $71 \%$ at 1 month, $61 \%$ at 3 months and 55\% at 6 months. At the end of the trial 31 of IER (58\%) and $46(85 \%)$ of CER subjects planned to continue the diet allocated at randomisation. Neither group received counselling on exercise, there was no overall change in physical activity in either group. 


\section{Changes in insulin sensitivity and associated markers}

Both groups experienced modest declines in fasting serum insulin and improvements in insulin sensitivity which were greater amongst the IER group (Table 4). Mean difference between groups [95\% CI] for fasting insulin was $-1.2[-1.4$ to -1.0$] \mu \mathrm{U} / \mathrm{ml},-16[-19$ to $-13] \%, \mathrm{P}=0.04$; and for insulin resistance was $-1.2[-1.5$ to -1.0$] \mu \mathrm{U} / \mathrm{mmol} / \mathrm{L},-45[-86$ to -3 ] \%, P=0.04) (Table 4). GEE modelling showed that the IER group had greater reductions in insulin resistance than the CER group at 3 months (mean difference [95\% CI] between groups -17 [ -33.2 to -0.2$] \%$, group by month 3 interaction, $\mathrm{P}=0.046)$ and 6 months (-23 [-38.1 to -8.6$] \%$, group by month 6 interaction, $\mathrm{P}=0.001)$ (Figure 2d). Correspondingly there was a modest increase in adiponectin in the IER group but not the CER group, (mean difference [95\% CI] +9 [ -2 to 21$] \%, \mathrm{P}=0.08$ ). Changes in the IGF-axis were comparable between the groups with increased IGFBP-1 and IGFBP-2 but negligible changes in total and free IGF-1.

Both groups experienced modest decreases in the inflammatory marker hsCRP, but no change in sialic acid levels. The groups had comparable reductions in the oxidative stress marker, fast acting AOPP by 6 months, which appeared to occur earlier in IER compared to CER. Slow acting AOPP appeared to decrease in the IER group and have a slight increase in the CER group (mean difference between groups at 6 month [95\% CI] -10 [-19 to 2] \%, $\mathrm{P}=0.12$ ). Women in the IER group had a non-significant greater increase in serum total ketone bodies at 6 months compared to the CER group suggesting higher rates of fat oxidation (mean difference between groups [95\% CI] $33[-8$ to 93$] \%, \mathrm{P}=0.12$ ). There were no significant changes in either group for ghrelin, the growth factor BDNF or for fasting glucose.

\section{Breast cancer risk markers}

Both groups experienced large reductions in serum leptin, decreases in the ratio of leptin: adiponectin, no changes in serum levels of testosterone, androstenedione and prolactin. The CER group had a greater reduction in DHEAS compared to IER (mean difference [95\% CI] CER vs. IER -6 [ -14 to 1$] \%, P=0.08$ ) however both groups experienced comparable increases in SHBG and a decrease in FAI (Table 5). Menstrual cycle data was available for 44 IER $(83 \%)$ and 47 CER $(87 \%)$. During the 6 month study period the mean $( \pm$ SD) length of menstrual cycle was significantly longer in the IER group compared to the CER group (29.7 [ \pm 3.8$]$ vs. $27.4[ \pm 2.7]$ days, $\mathrm{P}=0.002)$.

\section{Cardiovascular risk markers}

Both diets led to comparable reductions in total and LDL cholesterol, triglycerides, systolic and diastolic BP. Neither group experienced changes in HDL levels (Table 5)

\section{Effects of IER and CER on serum markers over one week}

A sub-set of women (15 IER and 9 CER) provided fasting serum samples over 1 week during the study period. The IER group demonstrated acute reductions in fasting insulin $(-23 \%)$, HOMA $(-29 \%)$ and triglycerides $(-18 \%)$, in the morning after the 2 day VLCD which normalised within 2 days of resuming normal diet. There were no significant changes in the CER group (Figure 3).

\section{Quality of life}

There were no major adverse effects of the diets. A small number of the IER group $(4,8 \%)$, but none of the CER group experienced minor adverse physical symptoms including lack of energy, headaches, feeling cold and constipation. Eight (15\%) of the IER and none of the CER complained of hunger, whilst a further $3(6 \%)$ of the IER and $7(13 \%)$ of the CER 
group reported increased energy and improved health. Eight (15\%) of the IER and 4 (7\%) of the CER group reported minor adverse psychological effects including lack of concentration, bad temper and preoccupation with food, whilst 17 (32\%) of the IER and 25 $(46 \%)$ of the CER group reported increased self confidence and positive mood. Predictably both groups acknowledged the limited food choice of the diets; 55\% IER and 53\% CER. More of the IER group reported problems fitting the diet into daily routine; $51 \%$ IER vs. $30 \%$ CER. RAND SF-36 quality of life scores were available for 96 patients at baseline (88\%), 91 at 1 and 3 months (84\%) and 75 at 6 months (69\%). There was a modest increase in the physical component summary score in the IER but not the CER group (mean difference $[95 \% \mathrm{CI}] 2.1$ [ -0.1 to 4.3$]$ units, 4 [0.0 to 8.0] \%, P=0.06). In comparison there was a slightly greater increase in the mental component summary score in the CER compared to the IER group (2.8 [0.1 to 5.6] units, 5 [0.0 to 12.0] \%, $\mathrm{P}=0.04$ ).

\section{Discussion}

\section{Main findings}

This is the largest randomised comparison of an isocalorific intermittent vs. continuous energy restriction to date in free living humans. Both approaches achieved comparable weight loss and improvements in a number of risk markers for cancer, diabetes and cardiovascular disease, for example reductions in fasting insulin, insulin resistance, leptin, the leptin: adiponectin ratio, free androgen index, inflammatory markers, lipids, blood pressure, increases in SHBG, IGFBP-1 and 2. IER was no easier to adhere to than CER, however it may be offered as an equivalent alternative to CER for weight loss and reducing disease risk.

\section{Comparison with other studies}

There has only been limited research of IER in humans. Two small short term (12 week) randomised studies have reported the effects of IER vs. CER. Ash et al compared an IER (4180 kJ liquid VLCD 4 days/week, 3 days ad libitum) vs. CER (6000 to $7000 \mathrm{~kJ} /$ day) amongst 9 men with type 2 diabetes and showed no difference in terms of weight or fasting insulin (20). Hill et al (19) compared alternating weeks of 2508, 3762, 5016 or $7254 \mathrm{~kJ} /$ day as compared to constant restriction of $5016 \mathrm{~kJ} /$ day in 16 moderately obese women and reported greater reductions in cholesterol in the IER group compared to the CER group $(-14$ vs. $-6 \%$ ). A further study amongst patients with type 2 diabetes showed beneficial effects of periodic VLCD (either 1 day/week or 5 consecutive days every 5 weeks) in addition to and not instead of a normal daily restriction ( 6180 to $7416 \mathrm{~kJ} /$ day). Predictably additional periods of VLCD led to greater weight loss, however the 5 day VLCD period had a beneficial effect on long term glycaemic control which was independent of weight change (42), suggesting possible metabolic benefits of IER.

In our study both IER and CER led to modest reductions in fasting serum insulin and improvements in insulin sensitivity which appeared greater in the IER group even 5 days after the 2 day VLCD. These parameters were predictably improved further during the 2 day VLCD, most likely linked to acute decreased levels of insulin and increased insulin receptor affinity with energy restriction (43). The biological significance of these improvements in insulin sensitivity in our population who were not particularly insulin resistant (only $16 \%$ of our subjects met the Diabetes Federation Criteria for the metabolic syndrome) is not known. IER appeared to bring about a modest increase in adiponectin which has a pivotal role in insulin sensitivity and the development and progression of cancer, heart disease and diabetes (44). We did not however observe any acute effects of IER on adiponectin, which contrasts to the $37 \%$ increase on alternate fasting days, previously reported amongst healthy weight men (45). 
Neither IER nor CER led to appreciable changes in total or free IGF-1. Animal studies have shown reductions in IGF-1 with CER but not consistently with IER (12) (46). BDNF is upregulated in inflammatory conditions and in the metabolic syndrome. Levels did not change with either of our test diets. Earlier studies have linked weight loss to decreased serum levels amongst overweight asthmatics (38) but increased levels amongst healthy overweight subjects (47). In our study both CER and IER led to the anticipated increases in serum levels of ghrelin (48).

Reductions in circulating sex steroid levels may reduce risk of breast cancer. The declines in FAI seen in both groups have been reported previously in premenopausal women (49). The greater reduction in DHEAS with CER may be advantageous and translate to greater reductions in breast cancer risk in women (50), in contrast to men where higher levels of DHEAS are linked to longevity (51). Conversely the greater average cycle length amongst the IER women may reduce breast cancer risk and reflect increased follicular length due to perturbations of the neuroendocrine axis (52). Neither group experienced changes in prolactin. Reductions in prolactin have previously been reported with much larger weight loss $(-15 \%)(53)$, thought to be due to enhanced dopamine 2 receptor activation. Reductions in the leptin: adiponectin ratio in both groups may be linked to improved insulin sensitivity (35)and reduced breast cancer risk(34).

Recent reviews speculate that IER may be associated with greater disease prevention than CER due to increased cellular stress resistance, in particular increased resistance to oxidative stress. This is thought to be mediated by 'hormesis' whereby the moderate stress of energy restriction increases the production of cytoprotective, restorative proteins, antioxidant enzymes and protein chaperones (54). Alternate day fasting has been linked to increased SIRT-1 gene expression in muscle (55), and to greater neuronal resistance to injury compared to CER in C57BL/6 mice (12). The tendency for greater improvements in oxidative stress markers in our IER than in the CER group may support these assertions. Declines in long term protein oxidation product aggregates suggest IER as a possible activator of catabolism and autophagy.

Both of our groups demonstrated good adherence and weight loss at 6 months (64\% IER and 55\% CER achieved $>5 \%$ weight loss) which may reflect the motivation of the participants and ongoing monitoring and motivational calls. A number of the IER group experienced minor adverse physical and mental symptoms with the IER. Despite this $57 \%$ were still undertaking either 1 or 2 milk days at 6 months, which is comparable but no better than adherence to long term popular diets (9). A recent blinded trial of a 2 day VLCD (1311 kJ/ day) reported no adverse effects on cognition, energy levels, sleep or mood (56), suggesting symptoms are expected with VLCD and therefore experienced and could potentially be overcome with appropriate counselling. Importantly IER did not lead to overeating on nonVLCD days. A similar lack of energy compensation has been reported after a 36 hour fast amongst healthy weight subjects (57).

\section{Strengths of study}

Previous reported weight loss and benefits of intermittent restriction have been reported from single arm studies $(38 ; 58)$. Our randomised trial allows the effects of IER to be directly compared with those of the standard CER approach and shows comparable benefits. Good retention to the study ( $83 \%$ at 6 months) and completeness of trial assessments means our LOCF analysis informs the relative acceptability and efficacy of the diets. We chose a pragmatic IER regimen which provided a $25 \%$ energy restriction and required a simple nonproprietary VLCD to be taken over 2 days/week. We believe this to be a more achievable than previously studied regimens of alternate days fasting or VLCD (38) (58;59). We tested the diets amongst overweight and obese free living individuals since this group is likely to 
derive metabolic benefit from energy restriction. We studied premenopausal women only to avoid the potential effects of sex or menopausal status on metabolic biomarkers. The benefits of IER and CER in older women or men cannot be extrapolated, however earlier reports suggest acceptability of intermittent VLCD may be greater amongst men than in women (42) (60).

\section{Study limitations}

Though longer than previous studies we did not assess the effects of IER and CER beyond 6 months to investigate their relative effects for maintenance of weight loss. Fewer of the IER group (58\%) planned to continue with the regimen beyond 6 months compared to the CER group $(85 \%)$ suggesting difficulties with long term adherence to IER. Further studies are needed to address issues related to adherence.

We assessed the effects of the two diets on a comprehensive range of serum biomarkers of disease risk. This approach does not take into account any local changes in production of these factors which may be more relevant to disease risk (61). Nor does it consider different isoforms of the hormones such as high molecular weight adiponectin and aceylated ghrelin (which are specifically linked to insulin sensitivity) (62).

\section{Implications and future studies}

Insulin sensitivity was assessed using HOMA which is an accepted method amongst nondiabetics (31). Future trials should however compare the effects of IER to CER in a prediabetic population using more rigorous methods to study insulin and glucose metabolism, for example glucose clamp techniques. The overall effects of IER on glycaemic control, for example both during and after IER each week compared to CER could also be ascertained from measuring HBA1c and fructosamine. Such studies could also examine the relative impacts of IER and CER on visceral, hepatic, intramuscular fat stores, and fat cell size which could preferentially decrease during the weekly spells of acute negative energy balance with IER(63) (64).

Our data is suggestive that periods of severe restriction may have different effects which may be important in the long term for disease prevention. However IER was no easier to adhere to than CER particularly in the longer term. Predictably, ease of following the diets varied between individuals. IER can be offered as an alternative to CER for reducing obesity and obesity-related disorders in some individuals. Psychosocial studies are required to better understand behavioural factors which can promote or reduce compliance to IER and CER regimens.

\section{Acknowledgments}

Michelle N. Harvie; Study conception and design, trial management and manuscript preparation

Mary Pegington; Running trial, statistical analysis and manuscript preparation

Mark P. Mattson; Consultation, assays at NIH and manuscript preparation

Jan Frystyk and Allan Flyvbjerg; Consultation, IGF-1 assays and manuscript preparation

Bernice Dillon; GEE modelling

Jack Cuzick; Design of trial, statistical advice and manuscript preparation

Gareth Evans; Recruitment of subjects, consultation and manuscript preparation

Susan Jebb; MRC HNR assays, consultation and manuscript preparation 
Bronwen Martin; BDNF and ghrelin assays and manuscript preparation

Roy G. Cutler; AOPP and total ketone bodies assays

Tae G. Son; AOPP and total ketone bodies assays

Stuart Maudsley; BDNF and ghrelin assay validation

Olga D. Carlson; Technical assistance with NIH assays

Josephine M. Egan; BDNF and ghrelin assay validation and manuscript preparation

Anthony Howell; Study conception and design, manuscript preparation

The authors would like to thank Julie Morris for her invaluable statistical advice, Helen Sumner for coordinating sample storage and processing, Rosemary Greenhaugh and Jenny Affen for assisting in recruitment and sample collection, Emma Campbell for quality of life analysis, Lorraine Darmody, Angela Foster, Jane Eaton and Philippa Quirk for clerical support, Padraig McQuaid for help with dietary analysis. Aram Rudenski for advise on the HOMA model. We dedicate this paper to Andrew Shenton (database manager) who died tragically, at a young age, on February 19th 2008.

Funding: Breast Cancer Campaign, World Cancer Research Fund, Genesis Appeal Manchester UK, Intramural Research Program of the National Institute on Aging of the NIH, The Danish Research Council for Health and Disease, Tanita Europe BV Middlesex UK for provision of Tanita TBF-300.

\section{Reference List}

1. Colditz GA, Willett WC, Rotnitzky A, Manson JE. Weight gain as a risk factor for clinical diabetes mellitus in women. Ann Intern Med. 1995; 122(7):481-486. [PubMed: 7872581]

2. Willett WC, Manson JE, Stampfer MJ, Colditz GA, Rosner B, Speizer FE, et al. Weight, weight change, and coronary heart disease in women. Risk within the 'normal' weight range. JAMA. 1995; 273(6):461-465. [PubMed: 7654270]

3. Beydoun MA, Beydoun HA, Wang Y. Obesity and central obesity as risk factors for incident dementia and its subtypes: a systematic review and meta-analysis. Obes Rev. 2008; 9(3):204-218. [PubMed: 18331422]

4. Renehan AG, Tyson M, Egger M, Heller RF, Zwahlen M. Body-mass index and incidence of cancer: a systematic review and meta-analysis of prospective observational studies. Lancet. 2008; 371(9612):569-578. [PubMed: 18280327]

5. Peeters A, Barendregt JJ, Willekens F, Mackenbach JP, Al Mamun A, Bonneux L. Obesity in adulthood and its consequences for life expectancy: a life-table analysis. Ann Intern Med. 2003; 138(1):24-32. [PubMed: 12513041]

6. Harvie M, Howell A, Vierkant RA, Kumar N, Cerhan JR, Kelemen LE, et al. Association of gain and loss of weight before and after menopause with risk of postmenopausal breast cancer in the Iowa women's health study. Cancer Epidemiol Biomarkers Prev. 2005; 14(3):656-661. [PubMed: 15767346]

7. Lindstrom J, Uusitupa M. Lifestyle intervention, diabetes, and cardiovascular disease. Lancet. 2008; 371(9626):1731-1733. [PubMed: 18502282]

8. Chlebowski RT, Blackburn GL, Thomson CA, Nixon DW, Shapiro A, Hoy MK, et al. Dietary fat reduction and breast cancer outcome: interim efficacy results from the Women's Intervention Nutrition Study. J Natl Cancer Inst. 2006; 98(24):1767-1776. [PubMed: 17179478]

9. Dansinger ML, Gleason JA, Griffith JL, Selker HP, Schaefer EJ. Comparison of the Atkins, Ornish, Weight Watchers, and Zone diets for weight loss and heart disease risk reduction: a randomized trial. JAMA. 2005; 293(1):43-53. [PubMed: 15632335]

10. Henry RR, Scheaffer L, Olefsky JM. Glycemic effects of intensive caloric restriction and isocaloric refeeding in noninsulin-dependent diabetes mellitus. J Clin Endocrinol Metab. 1985; 61(5):917925. [PubMed: 4044780] 
11. Kelley DE, Wing R, Buonocore C, Sturis J, Polonsky K, Fitzsimmons M. Relative effects of calorie restriction and weight loss in noninsulin-dependent diabetes mellitus. J Clin Endocrinol Metab. 1993; 77(5):1287-1293. [PubMed: 8077323]

12. Anson RM, Guo Z, de Cabo R, Iyun T, Rios M, Hagepanos A, et al. Intermittent fasting dissociates beneficial effects of dietary restriction on glucose metabolism and neuronal resistance to injury from calorie intake. Proc Natl Acad Sci U S A. 2003; 100(10):6216-6220. [PubMed: 12724520]

13. Cleary MP, Jacobson MK, Phillips FC, Getzin SC, Grande JP, Maihle NJ. Weight-cycling decreases incidence and increases latency of mammary tumors to a greater extent than does chronic caloric restriction in mouse mammary tumor virus-transforming growth factor-alpha female mice. Cancer Epidemiol Biomarkers Prev. 2002; 11(9):836-843. [PubMed: 12223427]

14. Berrigan D, Perkins SN, Haines DC, Hursting SD. Adult-onset calorie restriction and fasting delay spontaneous tumorigenesis in p53-deficient mice. Carcinogenesis. 2002; 23(5):817-822. [PubMed: 12016155]

15. Bonorden MJ, Rogozina OP, Kluczny CM, Grossmann ME, Grande JP, Lokshin A, et al. Crosssectional analysis of intermittent versus chronic caloric restriction in the TRAMP mouse. Prostate. 2009; 15;69(3):317-26.

16. Halagappa VK, Guo Z, Pearson M, Matsuoka Y, Cutler RG, Laferla FM, et al. Intermittent fasting and caloric restriction ameliorate age-related behavioral deficits in the triple-transgenic mouse model of Alzheimer's disease. Neurobiol Dis. 2007; 26(1):212-220. [PubMed: 17306982]

17. Mattson MP, Wan R. Beneficial effects of intermittent fasting and caloric restriction on the cardiovascular and cerebrovascular systems. J Nutr Biochem. 2005; 16(3):129-137. [PubMed: 15741046]

18. Sogawa $\mathrm{H}$, Kubo C. Influence of short-term repeated fasting on the longevity of female (NZB $x$ NZW)F1 mice. Mech Ageing Dev. 2000; 115(1-2):61-71. [PubMed: 10854629]

19. Hill JO, Schlundt DG, Sbrocco T, Sharp T, Pope-Cordle J, Stetson B, et al. Evaluation of an alternating-calorie diet with and without exercise in the treatment of obesity. Am J Clin Nutr. 1989; 50(2):248-254. [PubMed: 2667313]

20. Ash S, Reeves MM, Yeo S, Morrison G, Carey D, Capra S. Effect of intensive dietetic interventions on weight and glycaemic control in overweight men with Type II diabetes: a randomised trial. Int J Obes Relat Metab Disord. 2003; 27(7):797-802. [PubMed: 12821964]

21. Tyrer J, Duffy SW, Cuzick J. A breast cancer prediction model incorporating familial and personal risk factors. Stat Med. 2004; 23(7):1111-1130. [PubMed: 15057881]

22. Azziz R, Carmina E, Dewailly D, Diamanti-Kandarakis E, Escobar-Morreale HF, Futterweit W, et al. Positions statement: criteria for defining polycystic ovary syndrome as a predominantly hyperandrogenic syndrome: an Androgen Excess Society guideline. J Clin Endocrinol Metab. 2006; 91(11):4237-4245. [PubMed: 16940456]

23. Seiddell, J. Waist/hip and waist/thigh ratios. Fidanza, editor. London: Chapman and Hall; 1991. p. 24-29.

24. Ekelund U, Sepp H, Brage S, Becker W, Jakes R, Hennings M, et al. Criterion-related validity of the last 7-day, short form of the International Physical Activity Questionnaire in Swedish adults. Public Health Nutr. 2006; 9(2):258-265. [PubMed: 16571181]

25. Hays RD, Morales LS. The RAND-36 measure of health-related quality of life. Ann Med. 2001; 33(5):350-357. [PubMed: 11491194]

26. Anttila L, Koskinen P, Irjala K, Kaihola HL. Reference intervals for serum sex steroids and gonadotropins in regularly menstruating women. Acta Obstet Gynecol Scand. 1991; 70(6):475481. [PubMed: 1763613]

27. Tonolo G, Ciccarese M, Brizzi P, Milia S, Dessole S, Puddu L, et al. Cyclical variation of plasma lipids, apolipoproteins, and lipoprotein(a) during menstrual cycle of normal women. Am J Physiol. 1995; 269(6 Pt 1):E1101-E1105. [PubMed: 8572203]

28. Schofield WN. Predicting basal metabolic rate, new standards and review of previous work. Hum Nutr Clin Nutr. 1985; 39 (Suppl 1):5-41. [PubMed: 4044297]

29. Shai I, Schwarzfuchs D, Henkin Y, Shahar DR, Witkow S, Greenberg I, et al. Weight loss with a low-carbohydrate, Mediterranean, or low-fat diet. N Engl J Med. 2008; 359(3):229-241. [PubMed: 18635428] 
30. Avenell A, Sattar N, Lean M. ABC of obesity. Management: Part I--behaviour change, diet, and activity. BMJ. 2006; 333(7571):740-743. [PubMed: 17023467]

31. Matthews DR, Hosker JP, Rudenski AS, Naylor BA, Treacher DF, Turner RC. Homeostasis model assessment: insulin resistance and beta-cell function from fasting plasma glucose and insulin concentrations in man. Diabetologia. 1985; 28(7):412-419. [PubMed: 3899825]

32. Vermeulen A, Verdonck L, Kaufman JM. A critical evaluation of simple methods for the estimation of free testosterone in serum. J Clin Endocrinol Metab. 1999; 84(10):3666-3672. [PubMed: 10523012]

33. Friedewald WT, Levy RI, Fredrickson DS. Estimation of the concentration of low-density lipoprotein cholesterol in plasma, without use of the preparative ultracentrifuge. Clin Chem. 1972; 18(6):499-502. [PubMed: 4337382]

34. Chen DC, Chung YF, Yeh YT, Chaung HC, Kuo FC, Fu OY, et al. Serum adiponectin and leptin levels in Taiwanese breast cancer patients. Cancer Lett. 2006; 237(1):109-114. [PubMed: 16019138]

35. Finucane FM, Luan J, Wareham NJ, Sharp SJ, O'Rahilly S, Balkau B, et al. Correlation of the leptin: adiponectin ratio with measures of insulin resistance in non-diabetic individuals. Diabetologia. 2009; 52(11):2345-2349. [PubMed: 19756488]

36. Frystyk J, Skjaerbaek C, Dinesen B, Orskov H. Free insulin-like growth factors (IGF-I and IGF-II) in human serum. FEBS Lett. 1994; 348(2):185-191. [PubMed: 8034039]

37. Krassas GE, Pontikides N, Kaltsas T, Dumas A, Frystyk J, Chen JW, et al. Free and total insulinlike growth factor (IGF)-I, -II, and IGF binding protein-1, -2, and -3 serum levels in patients with active thyroid eye disease. J Clin Endocrinol Metab. 2003; 88(1):132-135. [PubMed: 12519841]

38. Johnson JB, Summer W, Cutler RG, Martin B, Hyun DH, Dixit VD, et al. Alternate day calorie restriction improves clinical findings and reduces markers of oxidative stress and inflammation in overweight adults with moderate asthma. Free Radic Biol Med. 2007; 42(5):665-674. [PubMed: 17291990]

39. Selmeci L, Seres L, Antal M, Lukacs J, Regoly-Merei A, Acsady G. Advanced oxidation protein products (AOPP) for monitoring oxidative stress in critically ill patients: a simple, fast and inexpensive automated technique. Clin Chem Lab Med. 2005; 43(3):294-297. [PubMed: 15843234]

40. Tworoger SS, Yasui Y, Chang L, Stanczyk FZ, McTiernan A. Specimen allocation in longitudinal biomarker studies: controlling subject-specific effects by design. Cancer Epidemiol Biomarkers Prev. 2004; 13(7):1257-1260. [PubMed: 15247140]

41. Alberti KG, Zimmet P, Shaw J. Metabolic syndrome--a new world-wide definition. A Consensus Statement from the International Diabetes Federation. Diabet Med. 2006; 23(5):469-480. [PubMed: 16681555]

42. Williams KV, Mullen ML, Kelley DE, Wing RR. The effect of short periods of caloric restriction on weight loss and glycemic control in type 2 diabetes. Diabetes Care. 1998; 21(1):2-8. [PubMed: 9538962]

43. Bar RS, Gorden P, Roth J, Kahn CR, De Meyts P. Fluctuations in the affinity and concentration of insulin receptors on circulating monocytes of obese patients: effects of starvation, refeeding, and dieting. J Clin Invest. 1976; 58(5):1123-1135. [PubMed: 993336]

44. Oh DK, Ciaraldi T, Henry RR. Adiponectin in health and disease. Diabetes Obes Metab. 2007; 9(3):282-289. [PubMed: 17391153]

45. Halberg N, Henriksen M, Soderhamn N, Stallknecht B, Ploug T, Schjerling P, et al. Effect of intermittent fasting and refeeding on insulin action in healthy men. J Appl Physiol. 2005; 99(6): 2128-2136. [PubMed: 16051710]

46. Varady KA, Roohk DJ, Hellerstein MK. Dose effects of modified alternate-day fasting regimens on in vivo cell proliferation and plasma insulin-like growth factor-1 in mice. J Appl Physiol. 2007; 103(2):547-551. [PubMed: 17495119]

47. Araya AV, Orellana X, Espinoza J. Evaluation of the effect of caloric restriction on serum BDNF in overweight and obese subjects: preliminary evidences. Endocrine. 2008 
48. Hayes MR, Miller CK, Ulbrecht JS, Mauger JL, Parker-Klees L, Gutschall MD, et al. A carbohydrate-restricted diet alters gut peptides and adiposity signals in men and women with metabolic syndrome. J Nutr. 2007; 137(8):1944-1950. [PubMed: 17634268]

49. Turcato E, Zamboni M, De Pergola G, Armellini F, Zivelonghi A, Bergamo-Andreis IA, et al. Interrelationships between weight loss, body fat distribution and sex hormones in pre- and postmenopausal obese women. J Intern Med. 1997; 241(5):363-372. [PubMed: 9183303]

50. Key T, Appleby P, Barnes I, Reeves G. Endogenous sex hormones and breast cancer in postmenopausal women: reanalysis of nine prospective studies. J Natl Cancer Inst. 2002; 94(8): 606-616. [PubMed: 11959894]

51. Enomoto M, Adachi H, Fukami A, Furuki K, Satoh A, Otsuka M, et al. Serum dehydroepiandrosterone sulfate levels predict longevity in men: 27-year follow-up study in a community-based cohort (Tanushimaru study). J Am Geriatr Soc. 2008; 56(6):994-998. [PubMed: 18422949]

52. Alvero R, Kimzey L, Sebring N, Reynolds J, Loughran M, Nieman L, et al. Effects of fasting on neuroendocrine function and follicle development in lean women. J Clin Endocrinol Metab. 1998; 83(1):76-80. [PubMed: 9435419]

53. Kok P, Roelfsema F, Langendonk JG, de Wit CC, Frolich M, Burggraaf J, et al. Increased circadian prolactin release is blunted after body weight loss in obese premenopausal women. Am J Physiol Endocrinol Metab. 2006; 290(2):E218-E224. [PubMed: 16144819]

54. Mattson MP. Hormesis defined. Ageing Res Rev. 2008; 7(1):1-7. [PubMed: 18162444]

55. Heilbronn LK, Civitarese AE, Bogacka I, Smith SR, Hulver M, Ravussin E. Glucose tolerance and skeletal muscle gene expression in response to alternate day fasting. Obes Res. 2005; 13(3):574581. [PubMed: 15833943]

56. Lieberman HR, Caruso CM, Niro PJ, Adam GE, Kellogg MD, Nindl BC, et al. A double-blind, placebo-controlled test of $2 \mathrm{~d}$ of calorie deprivation: effects on cognition, activity, sleep, and interstitial glucose concentrations. Am J Clin Nutr. 2008; 88(3):667-676. [PubMed: 18779282]

57. Johnstone AM, Faber P, Gibney ER, Elia M, Horgan G, Golden BE, et al. Effect of an acute fast on energy compensation and feeding behaviour in lean men and women. Int J Obes Relat Metab Disord. 2002; 26(12):1623-1628. [PubMed: 12461679]

58. Varady KA, Bhutani S, Church EC, Klempel MC. Short-term modified alternate-day fasting: a novel dietary strategy for weight loss and cardioprotection in obese adults. Am J Clin Nutr. 2009; 90(5):1138-1143. [PubMed: 19793855]

59. Heilbronn LK, Smith SR, Martin CK, Anton SD, Ravussin E. Alternate-day fasting in nonobese subjects: effects on body weight, body composition, and energy metabolism. Am J Clin Nutr. 2005; 81(1):69-73. [PubMed: 15640462]

60. Truby H, Baic S, deLooy A, Fox KR, Livingstone MB, Logan CM, et al. Randomised controlled trial of four commercial weight loss programmes in the UK: initial findings from the BBC "diet trials". BMJ. 2006; 332(7553):1309-1314. [PubMed: 16720619]

61. Liu YM, Lacorte JM, Viguerie N, Poitou C, Pelloux V, Guy-Grand B, et al. Adiponectin gene expression in subcutaneous adipose tissue of obese women in response to short-term very low calorie diet and refeeding. J Clin Endocrinol Metab. 2003; 88(12):5881-5886. [PubMed: 14671185]

62. St Pierre DH, Karelis AD, Coderre L, Malita F, Fontaine J, Mignault D, et al. Association of acylated and nonacylated ghrelin with insulin sensitivity in overweight and obese postmenopausal women. J Clin Endocrinol Metab. 2007; 92(1):264-269. [PubMed: 17062757]

63. Varady KA, Roohk DJ, Loe YC, McEvoy-Hein BK, Hellerstein MK. Effects of modified alternateday fasting regimens on adipocyte size, triglyceride metabolism, and plasma adiponectin levels in mice. J Lipid Res. 2007; 48(10):2212-2219. [PubMed: 17607017]

64. Kreier F, Fliers E, Voshol PJ, Van Eden CG, Havekes LM, Kalsbeek A, et al. Selective parasympathetic innervation of subcutaneous and intra-abdominal fat--functional implications. $\mathrm{J}$ Clin Invest. 2002; 110(9):1243-1250. [PubMed: 12417562] 


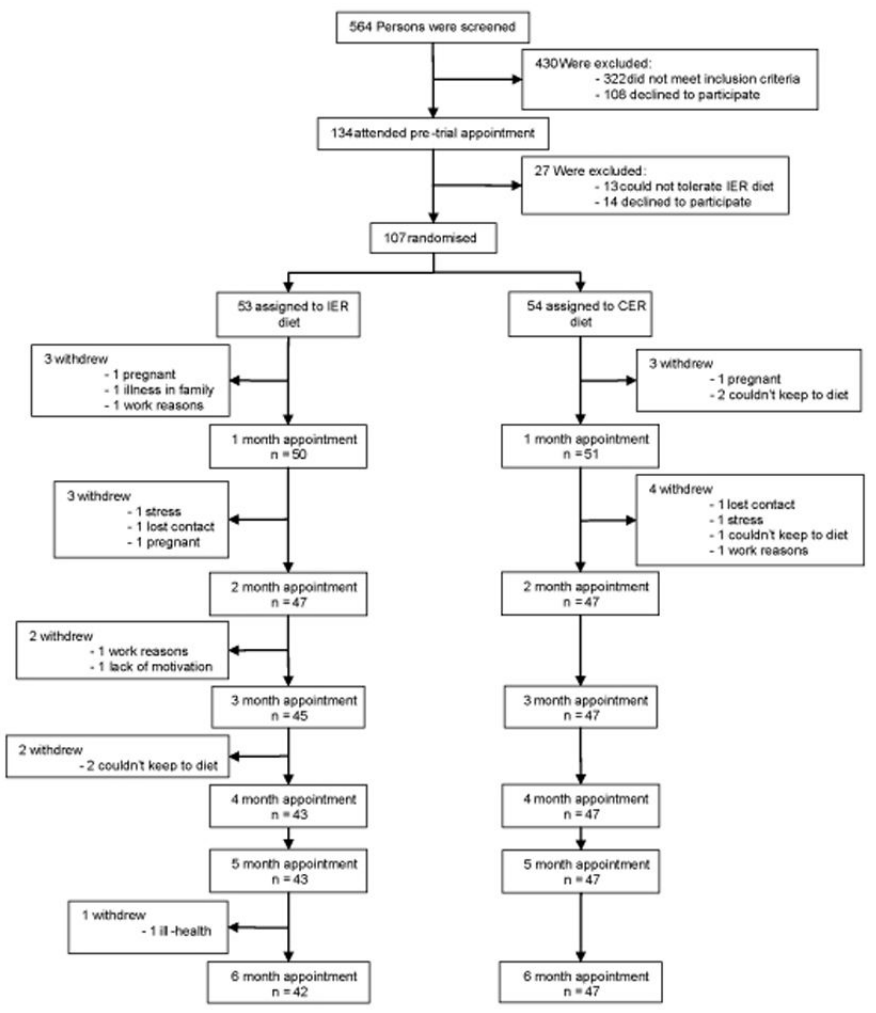

Figure 1.

Recruitment and retention to study 

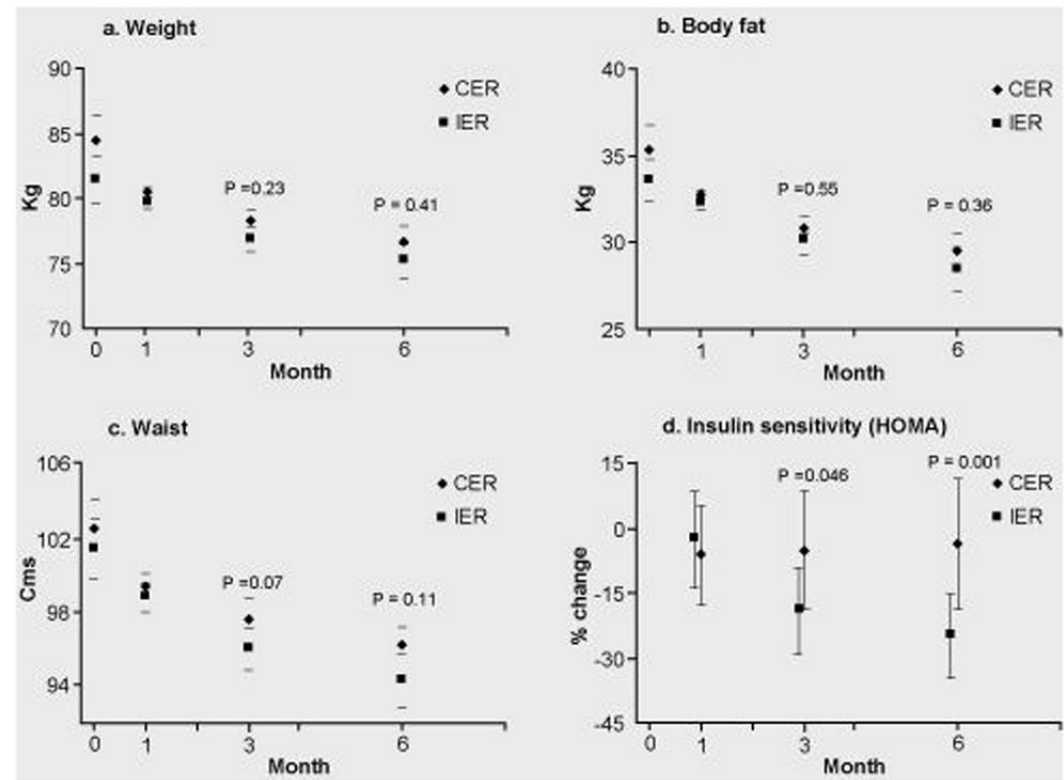

Figure 2. 

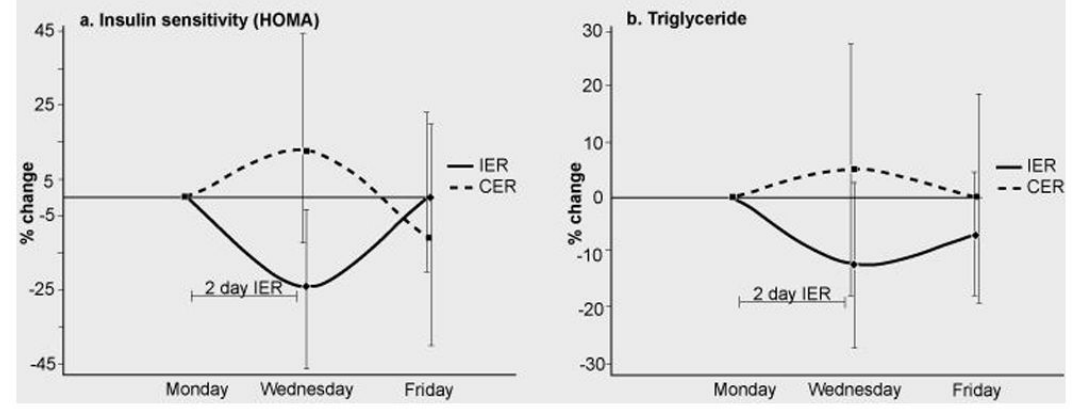

Figure 3 . 
Table 1

Baseline Characteristics of Subjects

\begin{tabular}{|c|c|c|c|}
\hline & $\begin{array}{l}\text { IER } \\
\mathrm{N}=\mathbf{5 3}\end{array}$ & $\begin{array}{l}\text { CER } \\
\mathrm{N}=54\end{array}$ & P Value \\
\hline Age at start (years) ${ }^{l}$ & $40.1(4.1)$ & $40.0(3.9)$ & 0.85 \\
\hline Baseline BMI $\left(\mathrm{kg} / \mathrm{m}^{2}\right)^{1}$ & $30.7(5.0)$ & $30.5(5.2)$ & 0.77 \\
\hline Weight gain since age $18(\mathrm{~kg})^{1}$ & $20.1(11.0)$ & $19.8(10.5)$ & 0.90 \\
\hline Family history of breast cancer (lifetime risk $>1$ in 6$)^{2,3}$ & $28(54 \%)$ & $30(56 \%)$ & 0.85 \\
\hline Sedentary $<1$ hour moderate activity/week ${ }^{2}$ & $23(44 \%)$ & $22(41 \%)$ & 0.70 \\
\hline Ethnic origin: ${ }^{2}$ & & & 0.21 \\
\hline Caucasian & $50(94 \%)$ & $53(98 \%)$ & \\
\hline Afro Caribbean & $1(2 \%)$ & $1(2 \%)$ & \\
\hline Other & $2(4 \%)$ & $0(0 \%)$ & \\
\hline Married $^{2}$ & $37(69 \%)$ & $39(72 \%)$ & 0.12 \\
\hline Children living at home ${ }^{2}$ & $52(98 \%)$ & $50(92 \%)$ & 0.55 \\
\hline Employment: ${ }^{2}$ & & & 0.32 \\
\hline Full-time & $47(88 \%)$ & $41(76 \%)$ & \\
\hline Part-time & $5(9 \%)$ & $10(19 \%)$ & \\
\hline Co morbidities: ${ }^{2}$ & & & 1.0 \\
\hline Asthma & $5(9 \%)$ & $5(9 \%)$ & \\
\hline Hypertension & $3(6 \%)$ & $2(3 \%)$ & \\
\hline Mild depression & $0(0 \%)$ & $1(2 \%)$ & \\
\hline Medication: $^{2}$ & & & 1.0 \\
\hline Anti-hypertensive & $3(6 \%)$ & $4(7 \%)$ & \\
\hline Anti-inflammatories & $2(4 \%)$ & $4(7 \%)$ & \\
\hline Steroid inhalers & $5(9 \%)$ & $1(2 \%)$ & \\
\hline Thyroxin & $1(2 \%)$ & $2(4 \%)$ & \\
\hline Anti-depressants & $1(2 \%)$ & $1(2 \%)$ & \\
\hline Beta blockers & $2(4 \%)$ & $1(2 \%)$ & \\
\hline
\end{tabular}

${ }^{l}$ Mean (SD), Independent sample $\mathrm{T}$ test

${ }^{2} \mathrm{~N}(\%)$, Chi Squared

3 Tyrer-Cuzick model (21) 


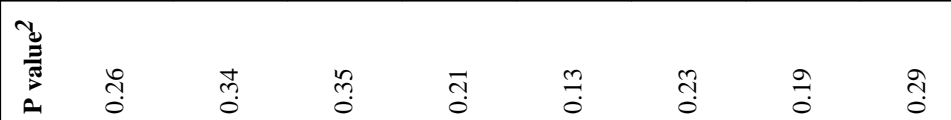




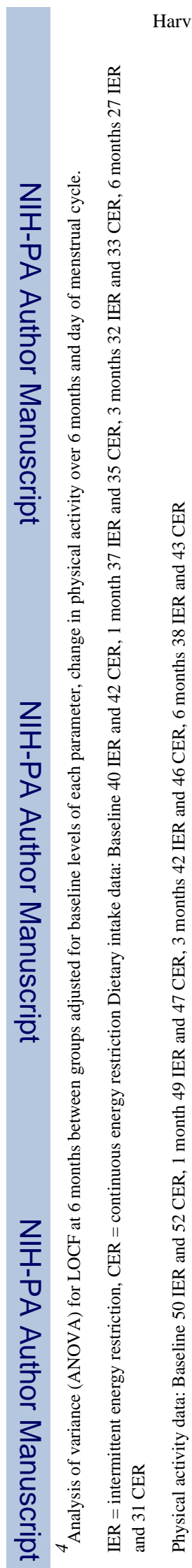

Page 22

Int J Obes (Lond). Author manuscript; available in PMC 2011 May 11. 


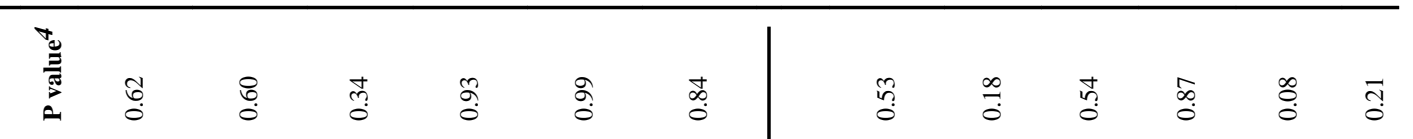

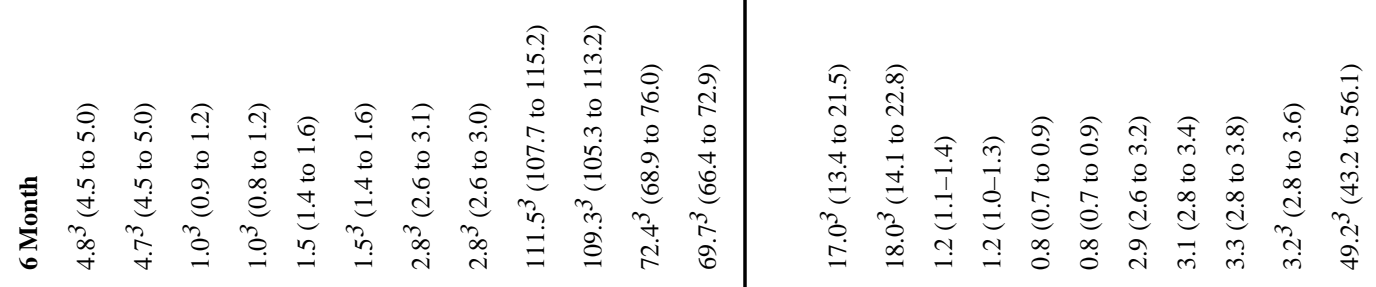
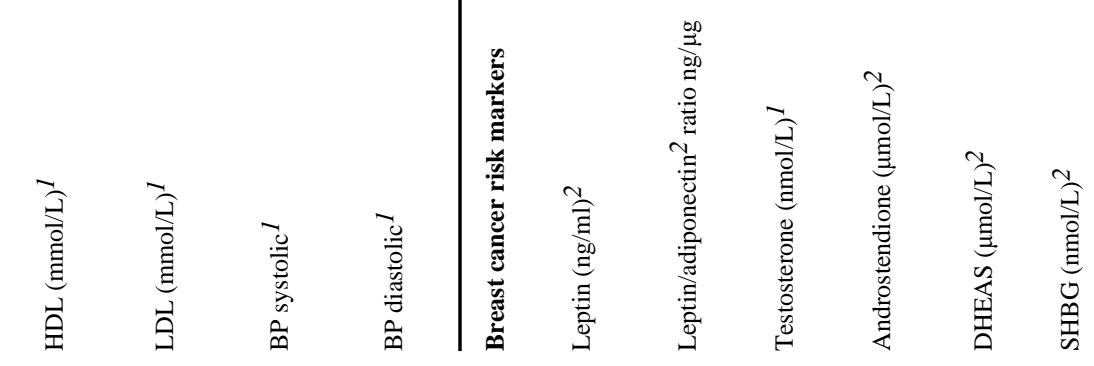


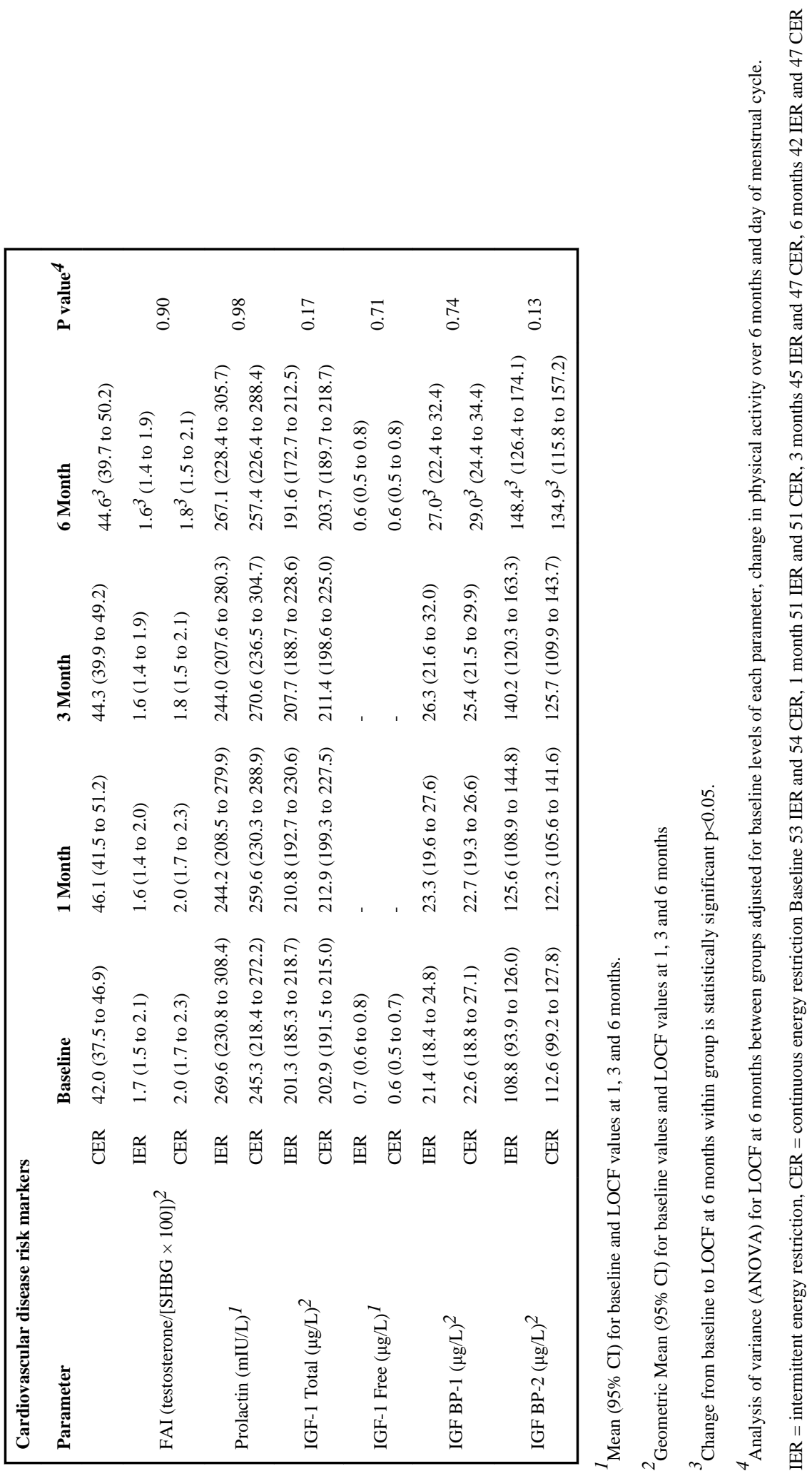

